DOI: https://doi.org/10.24867/02FA04Nemet

\title{
ENTERIJER COWORKING PROSTORA U SKLOPU OBJEKTA MEŠOVITE NAMENE U NOVOM SADU
}

\section{INTERIOR OF COWORKING SPACE WITHIN A MIXED-USE FACILITY IN NOVI SAD}

\author{
Dunja Nemet, Fakultet tehničkih nauka, Novi Sad
}

\section{Oblast - ARHITEKTURA}

Kratak sadržaj - Program rada se bavi oblikovanjem unutrašnjeg prostora $i$ dizajniranjem nameštaja za coworking prostor u Novom Sadu. Pored enterijera coworking prostora, objekat će imati razlicite funkcije za rad, odmor, relaksaciju, kulturu i obrazovanje, $i$ sve to čini multifunkcionalnu celinu. Rad obuhvata značenje $i$ funkcionisanje coworking prostora kao i pet studija slučaja objekata te namene.

Abstract - The project deals with the creation of interior space and the design of furniture for the coworking space in Novi Sad. In addition to the interior of the coworking space, the facility will have different functions for work, rest, relaxation, culture and education, all of which make the multifunctional whole. The work includes the meaning and functioning of coworking space as well as five case studies of objects for this purpose.

Ključne reči: Arhitektura, enterijer, dizajn, coworking, mešovita namena

\section{UVOD}

Tema rada je uređenje postojećeg prostora, u coworking prostor sa pratećim sadržajima, u zgradi bivšeg Radničkog univerziteta u ulici Vojvođanskih Brigada u Novom Sadu. Pri uređenju ovakvog prostora, akcenat se stavlja na efikasan i komforan način rada i pruža se korisnicima mogućnost slobode u odabiru mesta za sedenje, najčešće uz laptop ili računar. Pored radnog prostora, korisnicima se pruža mogućnost za odmor, relaksaciju i zabavu. Kroz rad će se istraživati razvoj prostora za rad i uticaj ekonomije, kulture, razvoja tehnologije i interneta, kao i sociološki uticaj i socijalni trendovi, na sve veću popularnost zakupljivanja ili iznajmljivanja mesta u coworking prostore.

Cilj istraživanja rada je stvaranje zajedničkog radnog prostora, kako bi mlade intelektualce podstakli na samostalni rad i finansijsku nezavisnost od velikih korporacija. Podsticaj preduzetništva, međusobne saradnje i razmene ideja je glavni cilj ovog načina poslovanja. U praktičnom delu rada, biće prikazan projekat coworking kancelarije sa različitim sadržajima koji još više doprinose kvalitetnijem radu takvom načinu poslovanja.

Zadatak istraživanja je otkrivanje novih oblika rada, zarad dovođenja radnika do aktivne saradnje, diskusije i bolje produktivnosti. Sve se to razvijalo od kalsičnih zatvorenih prostora, preko kubičnih formi i open space kancelarija.

\section{NAPOMENA:}

Ovaj rad proistekao je iz master rada čiji mentor je bila dr Ivana Miškeljin.
Kroz studije slučaja, koji mogu biti potpuno različiti kako vizuelno, tako i oblikovno, oni suštinski imaju isti cilj. Tako da će coworking biti prikazan kroz različite enterijere, koji svojim kvalitetima utiču ponaosob na svakog korisnika prostora, podstičući znanje, rad i ideju.

\section{ISTORIJSKI RAZVOJ RADNOG OKRUŽENJA}

Krajem 19. veka, prve komercijalne kancelarije su se pojavile u severnim industrijskim gradovima Amerike. Izumom telegrafa, zatim i telefona, kancelarije su imale mogućnost da se izmeste daleko od fabrike, a kontrola proizvodnje i distribucije je mogla da se održi i na udaljenim tržištima. Pojavom nove tehnologije, kao što je električno osvetljenje, pisaća mašina i kalkulator, omogućavale su akumulaciju velike količine informacija, koje su se obrađivale brže i efikasnije.

U Čikagu, čvorištu srednje zapadne američke železnice, tehnologija kao što su čelični ramovi i lift, omogućili su da objekti budu građeni na mnogo većim visinama, i samim tim je to omogućavalo da se izvuče maksimalan potencijal parcele. To su bile prve tradicionalno raspoređene, odvojene prostorije, koje se otvaraju ka hodnicima. Tlocrt je bio projektovan da se ostvari maksimalan prihod. Ovaj princip je usmeren isključivo na ostvarivanje profita i definiše projektovanje nebodera u Njujorku i Čikagu sa početka 20. veka.

Principi Modernizma su dovedeni u pitanje, još od 1950. godine. Po prvi put, arhitetkte i dizajneri se fokusiraju na unutrašnjost objekta i razmatraju mogućnost da raspored unutar radnog prostora može biti značajan faktor produktivnosti. Do tog trenutka, udobno sedenje se smatralo formom lenjosti. Takođe, same stolice su predstavljale status $\mathrm{u}$ kompanijama, pa tako nadređeni i zaposleni, kao i muškarci i žene nisu imali iste stolice. Tek tokom 70-ih godina, dizajneri se interesuju za principe ergonomije. Od tog trenutka kreće se sa teorijama o organizaciji radnog prostora tako da se u prvi plan stavljaju potrebe zaposlenih.

\subsection{Tradicionalna kancelarija}

Predstavljena je kao veliki prostor, koji je trajnim zidovima podeljen u brojne zasebne manje ili veće kancelarije, i to iz razloga onoga ko u njima radi [1]. Nadređeni ljudi u kompaniji, uglavnom su uživali u kancelarijama koje su se nalazile na uglovima objekta, sa dve strane zastakljenim zidovima i samim tim svetlijim i prozračnijim prostorom [1]. Podrazumeva se da su kancelarije imale veliku kvadraturu, i privatnost je bila logičan sled $u$ karakteru tih kancelarija [1].

Prednosti: koncentracija, nesmetan rad i privatnost [1] Mane: rigidna hijerarhija, mala fleksibilnost i nedostatak saradnje [1] 


\subsection{Kockice}

Kubične forme su delimično zatvoreni radni prostori, koji su odvojeni jedni od drugih pregradama, obično 1.5-1.8 metara visine, čija je svrha da izoluju radnike od pogleda $i$ buke $\mathrm{u}$ otvorenom radnom prostoru, tako da mogu da se koncentrišu na rad [1].

Šezdesetih godina prošlog veka, uslužna ekonomija i tehnologija se uporedo razvijaju i time značajno utiču na sliku radnog prostora [1]. Pokazalo se da se prostori koji su bili kruti u svojoj hijerarhijskoj organizaciji mogu izmeniti tako da budu motivacija za zaposlene [1]. Ovaj tip kancelarije, naveden u poglavlju iznad, dizajnirao je Robert Propst za firmu Herman Miller, 1967. godine, pod imenom Action Office II [1].

\subsection{Kuća kao kancelarija}

U devedesetim godinama, prošlog veka, rast interneta, laptop računara, i mobilnih telefona, signalizira smrt konvencijalne kancelarije [1]. Neke od najvećih konsultantskih i advertajzing kompanija, kancelarije su zamenile sa mobilnim telefonima i telekomunikacionom mrežom, tako da omogućavaju zaposlenima da se uključe bilo gde i rade virtuelan posao bilo kada [1]. Kako je tehnologija dopustila decentralizaciju radne snage, pojam korporativnog štaba počinje da zastareva [1].

\section{MODERAN PRISTUP RADNOM OKRUŽENJU}

Sa brzim razvojem novih tehnologija, novim načinima komunikacije i razmene informacija, mesta za rad kao i sam radni proces prolaze kroz sveobuhvatne promene. U isto vreme, razmera radne kancelarije se konstantno povećava prilagođavajući se modernim informacijama, znanju i društvu. Danas, na primer, su retke najjednostavnije zanatske radnje koje ne koriste kompjutere u radnom procesu, kao i za prodaju i računovodstvo. Proces rada se menja u kancelarijama, a jedan od glavnih ciljeva pri projektovanju objekata u kojima se nalaze kancelarije, je fleksibilnost i organizacija prostora tako da se ostvari bolja komunikacija među zaposlenima. Čest slučaj je da se napušta princip projektovanja poslovnih zgrada $u$ kojima su kancelarije malih površina, već se teži kancelarijama koje nemaju fiksna radna mesta, već zaposleni biraju željeno radno mesto za taj dan. Iako je praksa dokazala da je taj princip efikasniji za rad i bolji, realnost je da su većina kompanija i radnika naviknuti na standardne, male kancelarije, tako da teško napuštaju stare navike.

Ono što je bitno, jeste to da radna okolina koja je oblikovana na moderan i atraktivan način, čini značajan doprinos u komforu i motivaciji zaposlenih. Logično, ne može postojati jedna određena veličina kancelarije koja odgovara svima. Stimulativno radno okruženje koje promoviše produktivnost, prostorna organizacija koja omogućava socijalnu koheziju među zaposlenima, fleksibilnost, akustika, osvetljenje, kvalitetan vazduh i sobna temperatura su ključni parametri za ostvarenje komfora kod korisnika. Takođe, održivost je jedna od bitnih uloga u procesu projektovanja radnih prostora. Dizajn kancelarije i kvalitet, čine značajan doprinos stvaranju identiteta kompanije. Najaktuelnije i najzastupljenije moderno radno okruženje današnjice je u vidu coworking prostora.

\section{COWORKING}

Definicija coworking prostora je i dalje otvorena i generička. Coworking se karakteriše kao radna zajednica različitih preduzetnika i oblasti u okviru jednog objekta. Svi članovi zajedno postaju zajednica koja deli pogodnosti radnog prostora. Taj prostor uglavnom može biti u privatnom vlasništvu ili je potpuno autonoman. Coworking je stil koji zagovara fleksibilnost i saradnju koja je zasnovana na međusobnom poverenju i deljenju zajedničkih ciljeva i vrednosti među korisnicima. On je stvoren za nezavisne profesionalne aktivnosti.

Coworking prostori nude opremu, pogodnosti i prednosti koje ne mogu svi da priušte u svom poslu. Kod coworking prostora, preduzetnici dele jednu veliku kancelariju i koriste zajedničke usluge u zavisnosti od članstva: konferencijske sale, kancelarije "1 na 1", prostore za odmor, ormariće za odlaganje stvari, Wi-Fi, zajedničku upotrebu tehnologije: štampača, kopir mašine, faks mašine, kancelarijski pribor, zajedničku kuhinju ili bar, toalet i prostor za odmor, koji često podrazumeva društvene igre, stolove za stoni fudbal, tenis i slično, itd. Ovaj koncept rada, odgovara onim preduzetnicima koji ne žele da iznajmljuju sopstvene kancelarije, nemaju vremena i ne žele da se bave uređivanjem i izborom nameštaja ili izborom asistenata. Korisnici ovakvog prostora zakupljuju sto na određen vremenski period koji njima odgovara-na jedan dan, na nedelju dana, mesec dana ili godinu dana.

Ljudi koji su korisnici coworking prostora opisuju njihov način rada kao „kretanje“. Iako ovakvi prostori mogu varirati u zavisnosti od različitih usluga, svi oni dele četiri glavne vrednosti: "saradnja, otvorenost, komunikacija i održivost" [2]. Naglasak na zajednici je ključan.

Coworking prostori mogu se uporediti sa biznis inkubatorima-zajednički radni prostori kojim uglavnom upravlja lokalna vlast ili određene neprofitabilne organizacije koje imaju za cilj da stvore mogućnost za nove lokalne poslove. Ono u čemu je glavna razlika između ovih prostora je nedostatak socijalnog aspekta kod biznis inkubatora.

\subsection{Pozitivne i negativne strane coworking-a}

Coworking se pokazao kao dobro rešenje za sve one preduzetnike i honorarce kojima je u poslu nedostajao osećaj zajednice. Za razliku od ostalih poslovnih zajednica, coworkeri su najčešće individualci koji dele zajednički prostor. Spontani susreti ljudi iz različitih i sličnih struka i profesija se pokazalo kao veoma plodan i inovativan način rada i funkicionisanja u ovakvim prostorima.

Standardni coworking prostori nude:

- zajednički radni prostor,

- 24/7 pristup radu,

- mogućnost rezervisanja i zakupa kancelarija za sastanke,

- Wi-Fi,

- zajednička upotreba tehnologije: štampača, kopir mašine, faks mašine,

- zajednička kuhinja, toalet i prostor za odmor.

Ono što može da bude negativna strana ovakvog načina rada jeste autonomija. Previše autonomije može zapravo da zaustavi produktivnost i koncentraciju, jer ljudi nemaju rutinu. Ono što se kroz razvoj kancelarijskih prostora pokazalo kao velika mana otvorenih radnih prostora, jeste pojačana buka, koja dovodi do manjka koncentracije radnika, i smanjena privatnost. 


\section{KONCEPT}

Na teritoriji grada Novog Sada, postoji veliki potencijal za jednu ovakvu strukturu, jer Novi Sad predstavlja prestonicu kulture i sadrži visok stepen kulturnih udruženja i sadržaja. Takođe, Novi Sad je poznat centar IT industrije i to zahvaljujući odličnom odnosu cene i kvaliteta koji nudi stranim kompanijama. Zato broj frilensera raste iz dana $\mathrm{u}$ dan i pretenduje da postane najjača socijalno-privredna grana opštine.

Ideja ovog projekta jeste da se posao pretvori u zadovoljstvo i da se zaposleni, preduzetnici, umetnici i studenti povežu na jednom mestu i da svojom zajedničkom snagom i znanjem podstiču jedne druge na kvalitetan rad i međusobni odnos. U današnje vreme, neophodno je stvoriti prostor koji će pružiti fleksibilno i kvalitetno radno vreme, i da pored toga prijušti sadržaje za rad, relaksaciju, rekreaciju, zabavu, odmor, obedovanje i socijalizaciju. Ovaj prostor će koristiti frilenseri i preduzetnici (,sam svoj gazda“), ali ne samo oni, nego je cilj da se podstakne društvo da prošire svoja interesovanja i da svoje ideje realizuju.

Namene koje su predviđene da budu u sklopu objekta su rasprostranjene na više nivoa. Svaki nivo je predviđen za razvojni put kako u obrazovanju, tako i u ličnom razvoju studenta, preduzetnika,umetnika itd. Kroz niz radionica i škola za strane i programske jezike, zainteresovani se mogu pridružiti, bilo da su članovi/korisnici prostora ili ne. Poenta je da se na globalnom nivou širi svest građana.

\section{LOKACIJA}

Objekat bivšeg Radničkog univerziteta nalazi se u ulici Vojvođanskih brigada, u Novom Sadu. Prednost ove lokacije je to što nije na nekoj prometnoj trasi, već je uvučena, u malu ulicu koja pruža mir i tišinu za rad, ali je opet blizu svih aktuelnih dešavanja.

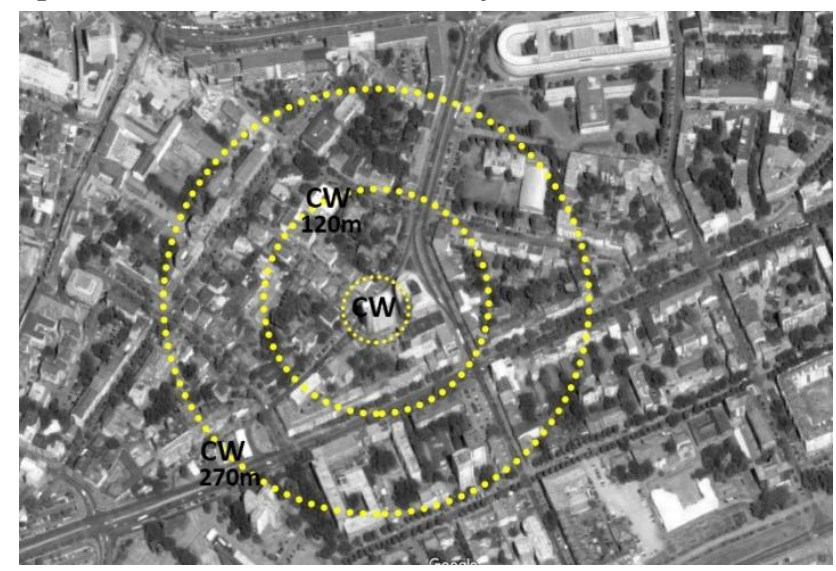

Slika 1. Prikaz lokacije

Da lokacija odgovara nameni, govori nam i to da se $u$ istoj ulici, Vojvođanskih brigada nalazi i Poslovni inkubator sa površinom od $100 \mathrm{~m}^{2}$, koji je namenjen coworking-u i prima 36 coworkera. $\mathrm{Na} 450 \mathrm{~m}$ od Poslovnog inkubatora, nalazi se Startit centar, na adresi Miroslava Antića 2, koji se nalazi gotovo u centru grada i pre svega je namenjen IT stručnjacima.

Postojanje coworking prostora na ovoj lokaciji je od velikog značaja za dalji razvoj coworking zajednice Novog Sada i njegove okline. Ima potencijal da postane prostor u kojem bi unapređenje poslovanja mogli da ostvare kako frilenseri, tako i kompanije koje rade po starom sistemu rada. $\mathrm{U}$ blizini se nalaze velike privatne $\mathrm{i}$ državne firme, banke i univerzitetski kampus.

\section{PROGRAMSKO-FUNKCIONALNA STRUKTURA}

Postojeća skeletna konstrukcija bivšeg Radničkog univerziteta predstavlja jednu celinu. Prilikom projektovanja. kombinovane su različite funkcije, kako bi objekat bio samoodrživ. On je predviđen da pored svoje glavne namene (coworking prostor) bude i prostor za rad, obrazovanje, relaksaciju, rekreaciju, obedovanje i zabavu.

Objekat se sastoji od visokog prizemlja sa galerijom i 11 spratova. Struktura se razlikuje po sadržajima u prizemlju i na ostalim spratovima. Sadržaji su prilagođeni po vertikali, zbog vizura koje se pružaju na Petrovaradinsku tvrđavu, Dunav, Univerzitetski grad i sam centar grada. Osnove su pravougaone i prostor nema nikakve barijere tako da ima mogućnosti da se kvalitetno osmisli koncept open space-a. Fasada se neće menjati, iz razloga da se vizure ne bi narušile i ostaje kakva je i bila, staklena opna. Novoprojektovana struktura teži da se nadoveže na postojeću strukturu i u potpunosti je iskoristi bez narušavanja. Tako u celosti dozvoljava sagledivost kako spoljašnjosti, tako i unutršnjosti prostora.

\section{MATERIJALIZACIJA}

Podna obloga- Javni objekti imaju kriterijume za odabir podne obloge. Radi lakog održavanja i otpornosti na habanje, primenjena je tehnika izlivanja poda. Liveni pod je cementna košuljica tretirana epoksi-premazima, koja se kompresorom izliva i ravna helikopterom. Upotrebljena je Microtipping tehnika, koja je u potpunosti monolitna i bez fugni. To je materijal koji je sastavljen od tečnog polimera i karakteristične cementne mešavine, i može se nanositi i preko starih pločica, parketa ili betona, debeo svega $3 \mathrm{~mm}$. Ovaj pod je otporan na udarce, abraziju i pritisak, usporava prodiranje vode i pogodan je kao završni sloj poda preko podnog grejanja. Zidna obloga- Cilj radnog prostora, jeste da postigne bojama mir i prijatnu atmosferu za rad, koja neće odvalčiti pažnju i ometati koncentraciju korisnika. U samom prostoru nema mnogo punih zidova, jer je fasada staklena, tako da ono što je okrečeno su samo parapeti i pregradni zidovi. Boje koje su odabrane za zidove su svetle, uglavnom bele boje, kako bi istakle ostale detalje u prostoru, kao što su mobilijar i zelenilo. Plafoni su okrečeni u beloj boji, kako bi utisak o visini prostora bio što veći. Stubovi i parapeti su urađeni u teksturi natur betona, svetlo sive boje, i predstavlja akcenat na arhitektonske elemente i samu istoriju tog objekta.

\section{MOBILIJAR}

$\mathrm{U}$ ulaznom delu, prijemni deo je istaknut custom made masivnim, drvenim pultom od hrasta koji je akcentovan sa metalnom mrežastom strukturom u tamno sivoj boji. Dimenzije pulta su ŠxVxD=200x75x90cm. Stolica je brenda Normann Copenhagen, dizajnera Simon Legald.

U delu za samostalni rad predviđeno je da svako ima svoj sto sa stolicom i na zidu dve police i tablu za zapisivanje ideja. Sto i stolica su brenda Vitra, dizajnera Jean Prouve. 
U delu za zajednički rad, stolovi su custom made pravouganog oblika, dimenzija $\breve{S} x V x D=150 \times 75 \times 65 \mathrm{~cm}$. Materijal koji je za ploču stola korišćen je hrast, a za noge čelik crne boje. Stolice su žute boje sa aluminijumskim crnim nogama.

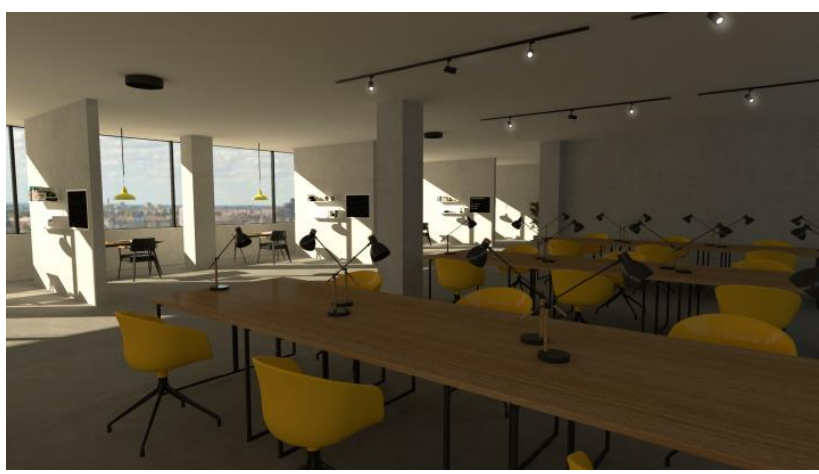

Slika 2. Prikaz enterijera coworking prostora

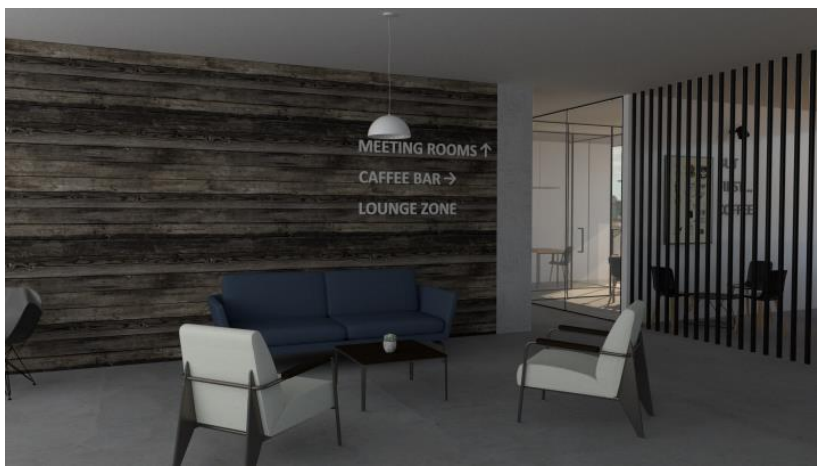

Slika 3. Prikaz enterijera lounge zone

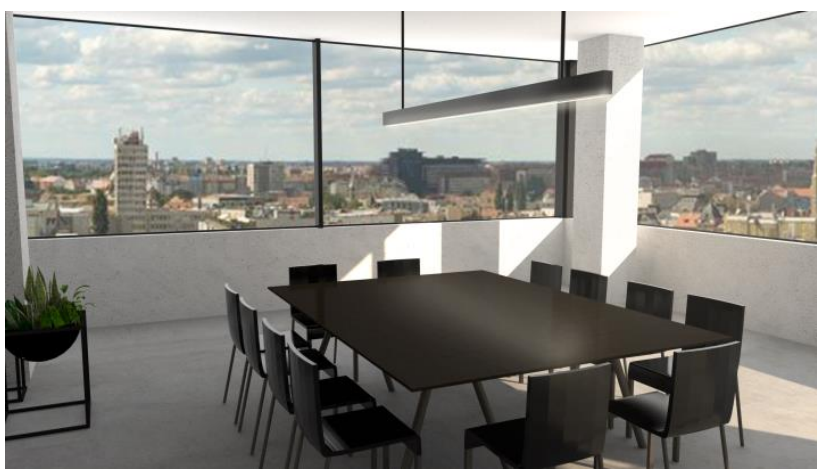

Slika 4. Prikaz enterijera konferencijske sale

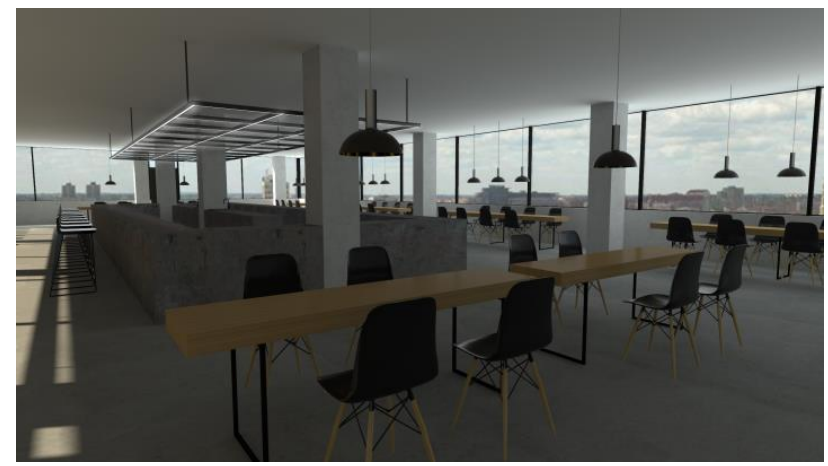

Slika 5. Prikaz enterijera restorana

\section{ZAKLJUČAK}

Novi Sad kao evropski grad kulture, ima veliki potencijal da privuče mlade intelektualce iz sveta i zemljecoworkere, kako bi poboljšao kulturni i socijalni život mladih frilensera iz raznih oblasti umetnosti, marketinga, IT sektora i preduzetnike u coworking prostore. Samim tim što je studentski grad, pruža mogućnost velikom broju mladih da se usavršavaju i da svoje znanje dižu na viši nivo koristeći takve prostore za rad. Coworking uveliko sprečava odliv mladih iz zemlje, jer pruža dalji razvoj stručnjaka na teritoriji, zbog čega ovih prostora treba da bude što više, kako u većim gradovima, tako i u ruralnim sredinama gde se pokazalo da je i te kako postignut pozitivan rezultat i uspeh u razvoju coworking zajednica.

Projektujući ovakve strukture koje će primiti različite funkcije: rad, odmor, rekreacija, kultura, obrazovanje i zabava i spojiti ih u visokofunkcionalnu celinu, govori nam u kakvom vremenu danas živimo i koje su sve potrebe društva. Ono što će radnika zadržati u ovakvom prostoru je pre svega pažnja koja je posvećena dizajnu i ergonomiji ovih prostora, kao i funkcionalnost koja je na prvom mestu, opremljenost, itd. Sve to će mu omogućiti da bira radno okruženje koje će uticati na njegov efikasan i nesmetan rad i neće ga vraćati i odbijati da se vrati u klasične kancelarije ili radu od kuće.

$\mathrm{U}$ današnje vreme, razvojem interneta i potpunom promenom načina rada, potrebno je posedovati coworking prostore jer oni pružaju potpuno nesmetano obavljanje posla i iznajmljivanje radnog stola uz siguran $W i-F i$ i ostalu opremu nove tehnologije. Korisnici ovakvih prostora su ili prinuđeni da menjaju radni prostor, ili ne žele da se bave uređivanjem i izborom nameštaja svog radnog prostora ili su to oni koji prosto žele da poboljšaju kvalitet života i rada, razmenjujući ideje sa kolegama iz istih oblasti van granica svog grada ili države.

Na kraju, možemo se složiti sa činjenicom da coworking predstavlja budućnost poslovanja koje je već uveliko zastupljeno kod nas, i koje ima veliku pozitivnu stranu svog postojanja i delovanja.

\section{LITERATURA}

[1] A. Kotlyarov, History of the Office, 2015.

[2] Brad Reed, Co-working: the ultimate in teleworking flexibility, Network World, 2007.

\section{Kratka biografija:}

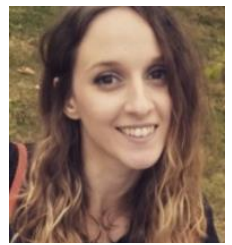

Dunja Nemet rođena je 1991. godine u Zrenjaninu. Zvanje diplomirani inženjer arhitekture stiče 2017. godine Master rad brani iz oblasti Dizajn enterijera na FTN-u u Novom Sadu, 2018. godine. 